\title{
Clinical Features of Hypertensive Patients With Covid-19 Compared With a Normotensive Group
}

shuang wang

Changshou people's hospital,chongqing china https://orcid.org/0000-0003-2962-6798

qiang zhang

changshou people's hospital, chongqing,china

zhao bin zheng ( $\sim 156313750 @ q q . c o m$ )

https://orcid.org/0000-0002-9093-0062

peng wang

changshou people's hospital, chongqing,china

hua hong ye

changshou people's hospital, chongqing,china

xiao qing jing

changshou people's hospital, chongqing,china

jun hua zhang

changshou people's hospital, chongqing,china

da yu fan

changshou people's hospital, chongqing,china

ping jia

changshou people's hospital, chongqing,china

zhong dan zhang

changshou people's hospital, chongqing china

ting ting luo

Chongqing Three Gorges University

shi sheng zhu

Chongqing Medical and pharmaceutical college

Research article

Keywords: COVID-19, hypertension, clinical features, ACEI/ARB

Posted Date: June 13th, 2020

DOI: https://doi.org/10.21203/rs.3.rs-31685/v1 
License: (c) (i) This work is licensed under a Creative Commons Attribution 4.0 International License. Read Full License 


\section{Abstract}

Background: The novel coronavirus (COVID-19), which began in Wuhan, China, in December 2019, has spread worldwide and poses a great threat to human health. Among COVID-19 patients, those with hypertension have been reported to have higher morbidity and mortality. This study was conducted to provide the international community with a deeper understanding of COVID-19 with hypertension.

Methods: A total of 188 COVID-19 patients were studied from January to March 2020. The epidemiology, clinical features, and laboratory data of hypertensive patients with COVID-19 were collected, retrospectively analyzed, and compared with a normotensive group. The use of anti-hypertensive drugs, general treatment, and clinical outcomes of hypertensive patients were also analyzed.

Results: The median ages in hypertensive patients with mild and severe COVID-19 were both significantly greater than the median age in the normotensive group. But there was no significant gender difference between the hypertensive and normotensive groups. All patients had lived in the Wuhan area. Common symptoms of all of the patients included fever, cough, and fatigue. Chest CT scans showed bilateral patchy shadows or ground glass opacity in the lungs of all of the patients. All (98 [100\%]) of the hypertensive patients received antiviral therapy (Arbidol was used alone or in combination with Ribavirin), antibiotic therapy (85 [86.7\%]), and corticosteroids (31 [31.6\%]). It has been suggested that the combination of Arbidol and Ribavirin as initial therapy for hypertensive patients with COVID-19 is effective and safe. There were no significant differences in laboratory data between the mild cases in the hypertensive and the normotensive groups. In the severe cases, the hypertensive patients had higher plasma levels of D-dimer, C-reactive protein (CRP), and Interleukin-6 (IL-6) $(P<0.05)$. Furthermore, the hypertensive patients who were treated with angiotensin-converting enzyme inhibitors/angiotensin receptor blockers (ACEI/ARB) had no statistically significant differences between the mild and severe groups $(p>0.05)$.

Conclusion: In this study, we demonstrated that the hypertensive patients who were treated with ACEI/ARB did not have an increased risk of developing severe COVID-19. Arbidol and Ribavirin played an important role in the treatment of the viral pneumonia. Hypertensive patients with severe viral pneumonia had stronger inflammatory responses than non-hypertensive patients.

\section{Background}

In December 2019, a series of cases of pneumonia of unknown cause began in Wuhan, China, and this disease now is spreading to the rest of the world [1]. As of May 5, 2020, around 3,308,678 cases of coronavirus disease 2019 (COVID-19) and 234,123 deaths have been reported [2]. Coronaviruses are enveloped, single-stranded, positive-sense RNA viruses that can be found in many species including humans, other mammals, and birds. They may cause acute respiratory distress syndrome and multiorgan dysfunction $[3,4]$. Human pathogenic coronaviruses (severe acute respiratory syndrome coronavirus [SARS-CoV] and SARS-CoV-2) bind to their target cells through angiotensin-converting 
enzyme 2 (ACE2), which is expressed by epithelial cells of the lung, intestine, kidney, and blood vessels [5]. The function of this enzyme is to catalyze the conversion of angiotensin II to angiotensin 1-7, a peptide that opposes the pro-inflammatory, pro-oxidative, vasoconstrictive, and fibrotic properties of angiotensin II [6]. Hypertensive patients often show decreased expression of ACE2, which suggests that hypertension may be involved in the pathogenesis of COVID-19. A literature review was performed, and it was found that there have been no studies regarding the characteristics of hypertensive patients infected with COVID-19. The most common symptoms of the disease are fever, dry cough, and fatigue. Pulmonary imaging has shown multiple ground glass shadows in both lungs. Severe cases have been shown to develop into acute respiratory distress syndrome (ARDS) and other serious complications, eventually leading to multiple organ failure. Scientists have successfully isolated the pathogen that causes the pneumonia of COVID-19 [7,8]. The new ß-coronavirus was named 2019 severe acute respiratory syndrome coronavirus 2 (SARS-CoV-2), and the WHO named the disease Coronavirus Disease (COVID19). COVID-19 rapidly spread throughout the country of China, and the number of infected people gradually increased worldwide.

This study's aim was to describe the epidemiological and clinical features, laboratory findings, radiological characteristics, treatment, and outcomes of COVID-19 patients with hypertension. It is hoped that these findings will assist the global community to understand more clearly and treat this new infectious disease.

\section{Methods}

\section{Patients}

In late December 2019, several hospitals of Wuhan reported clusters of patients with pneumonia of unknown cause, which was identified as SARS-CoV-2 soon after. Wuhan Central Hospital had received a large number of patients infected with SARS-CoV-2 because it is the closest to the South China seafood market where the initial infection occurred. Generally, the patients at Central Hospital come from all regions of Wuhan, especially the Hankou district. In this study, all consecutive patients with confirmed COVID-19 admitted to the main campus of Wuhan Central Hospital from January to March 2020 were enrolled. All patients with COVID-19 enrolled in this study were diagnosed and admitted in accordance with the guidelines of the National Health Commission of China [9].

\section{Data collection}

We collected the clinical data of patients using the electronic medical record system (HIS). General information included clinical symptoms, physical signs, laboratory results, chest CT manifestations, treatment measures, complications, and other parameters. The patients were divided into mild and severe groups. The mild group had symptoms of fever and respiratory tract symptoms, and imaging showed a little ground glass shadow in both lungs. The severe group had respiratory distress, $R R \geq 30$ 
breaths/minute in a resting state, a mean oxygen saturation of $\leq 93 \%$, and an arterial blood oxygen partial pressure $(\mathrm{PaO} 2)$ /oxygen concentration $(\mathrm{FiO} 2) \leq 300 \mathrm{mmHg}$.

\section{Coronavirus detection}

All of the suspected cases were detected by RT-PCR of throat swab samples, and those who were positive for the coronavirus RNA were identified as confirmed cases. Throat swab samples of the patients were collected, and COVID-19 was detected using a novel coronavirus 2019-nCoV nucleic acid detection kit (fluorescent PCR) (Suzhou Tianlong Biotechnology Co., Ltd., Jiangsu, China). The throat swab samples, primers, fluorescent probes, reaction buffer, and enzyme mixture were prepared in a reaction system according to standard procedure, and then amplified according to the following settings: 1) $50^{\circ} \mathrm{C}, 30 \mathrm{~min}$; 2) $\left.95^{\circ} \mathrm{C}, 10 \mathrm{~min} ; 3\right) 94^{\circ} \mathrm{C}, 15 \mathrm{~s} \rightarrow 50^{\circ} \mathrm{C}, 30 \mathrm{~s} \rightarrow 72^{\circ} \mathrm{C}, 30 \mathrm{~s}, 5$ cycles; 4$) 94^{\circ} \mathrm{C}, 10 \mathrm{~s} \rightarrow 58^{\circ} \mathrm{C}, 30 \mathrm{~s} ; 35$ cycles.

\section{Statistical analysis}

Continuous variables were described using the median (IQR) and compared with the Mann-Whitney U test. The continuous variables were compared using independent group $t$ tests when the data were normally distributed. The proportions of categorical variables were compared using a $\chi 2$ test. Statistical analysis was performed with SPSS software (version 20.0). A P-value of less than 0.05 was considered to indicate statistical significance. All probabilities are two-tailed.

\section{Results}

\section{Clinical characteristics}

The enrolled 98 hypertensive patients and 90 non-hypertensive patients were all confirmed infected with COVID-19 using PCR tests of throat swabs. The median ages of hypertensive patients with mild and severe COVID-19 were both significantly higher than the median age of normotensive patients (mild group: 61 years [IQR, 56-67] vs. 52 years [IQR, 41-63], $\mathrm{P}=0.016$; severe group: 67 years [IQR, 61-74] vs. 60 years [IQR, 57-67], $\mathrm{P}=0.007$, Table 1 ). In the mild COVID-19 group with hypertension, 18 patients (31.6\%) were men, and 39 patients $(68.4 \%)$ were women, which was not statistically significantly different than in the normotensive group (28 patients [48.2\%] were men, and 30 patients [51.8\%] were women, $p=$ 0.068). In the severe COVID-19 group with hypertension, 22 patients $(53.7 \%)$ were men, and 19 patients (46.3\%) were women; this observation was also not significantly different than with the normotensive group (14 patients [43.9\%] were men, and 18 patients [56.1\%] were women, $p=0.401$ ). The characteristics of the hypertensive group versus the non-hypertensive group on admission are provided in Table 1 . The normotensive and hypertensive group both had a high percentage of complications of diabetes and cardiovascular disease on admission. Compared to the normotensive group, the hypertensive group had higher prevalence of fever, cough, and fatigue at presentation. 
Table 1

Comparison of characteristics and symptoms between the hypertensive and non-hypertensive groups infected with COVID-19

\begin{tabular}{|c|c|c|c|c|c|c|}
\hline & Hypertension & Normotension & & Hypertension & Normotension & \\
\hline & $\begin{array}{l}\text { Mildly ill } \\
\text { cases }\end{array}$ & $\begin{array}{l}\text { Mildly ill } \\
\text { cases }\end{array}$ & $\begin{array}{l}P \\
\text { value }\end{array}$ & $\begin{array}{l}\text { Severely ill } \\
\text { cases }\end{array}$ & $\begin{array}{l}\text { Severely ill } \\
\text { cases }\end{array}$ & $\begin{array}{l}P \\
\text { value }\end{array}$ \\
\hline & $(n=57)$ & $(n=58)$ & & $(n=41)$ & $(n=32)$ & \\
\hline Age (years) & $61(56-67)$ & $52(41-63)$ & 0.001 & $67(61-74)$ & $60(57-67)$ & 0.007 \\
\hline \multicolumn{7}{|l|}{ Sex } \\
\hline Men & $18(31.6 \%)$ & $28(48.2 \%)$ & 0.068 & $22(53.7 \%)$ & $14(43.9 \%)$ & 0.401 \\
\hline Women & 39 (68.4\%) & 30 (51.8\%) & 0.068 & $19(46.3 \%)$ & $18(56.1 \%)$ & 0.401 \\
\hline \multicolumn{7}{|l|}{ Comorbidity } \\
\hline Hypertension & $57(100 \%)$ & 0 & & $41(100 \%)$ & 0 & \\
\hline Diabetes & $8(14 \%)$ & $9(15.5 \%)$ & 0.823 & 16 (39\%) & 12 (37.5\%) & 0.894 \\
\hline $\begin{array}{l}\text { Cardiovascular } \\
\text { disease }\end{array}$ & $5(8.8 \%)$ & $5(8.6 \%)$ & 0.977 & $9(22 \%)$ & 7 (21.9\%) & 0.994 \\
\hline $\begin{array}{l}\text { Cerebral } \\
\text { infarction }\end{array}$ & $3(5.3 \%)$ & $2(3.4 \%)$ & & $6(14.6 \%)$ & $8(25 \%)$ & 0.264 \\
\hline $\begin{array}{l}\text { Chronic } \\
\text { obstructive } \\
\text { pulmonary } \\
\text { disease }\end{array}$ & $2(3.5 \%)$ & 0 & & $3(7.3 \%)$ & $2(6.3 \%)$ & \\
\hline Malignancy & 0 & $2(3.4 \%)$ & & $1(2 \%)$ & $2(6.3 \%)$ & \\
\hline \multicolumn{7}{|l|}{$\begin{array}{l}\text { Signs and } \\
\text { symptoms }\end{array}$} \\
\hline Fever & $40(70.2 \%)$ & 38 (65.6\%) & 0.593 & $22(53.7 \%)$ & 17 (53.1\%) & 0.964 \\
\hline \multicolumn{7}{|l|}{$\begin{array}{l}\text { Highest } \\
\text { temperature, } \\
{ }^{\circ} \mathrm{C}\end{array}$} \\
\hline$<37.3$ & 17 (29.8\%) & $20(34.4 \%)$ & 0.593 & $19(46.3 \%)$ & $15(46.9 \%)$ & 0.964 \\
\hline $37.3-38.0$ & 27 (47.4\%) & 28 (48.3\%) & 0.922 & $15(36.6 \%)$ & $10(25 \%)$ & 0.634 \\
\hline $38.1-39$ & $7(12.3 \%)$ & $9(15.5 \%)$ & 0.616 & $5(12.2 \%)$ & $4(12.5 \%)$ & \\
\hline$>39$ & $6(10.5 \%)$ & $1(1.7 \%)$ & & $2(4.9 \%)$ & $3(9.4 \%)$ & \\
\hline Cough & 55 (96.5\%) & 52 (89.7\%) & & 31 (75.6\%) & 26 (81.3\%) & 0.563 \\
\hline Fatigue & $52(91.2 \%)$ & 38 (65.5\%) & 0.001 & 28 (68.3\%) & $17(53.1 \%)$ & 0.186 \\
\hline
\end{tabular}




\begin{tabular}{|c|c|c|c|c|c|c|}
\hline & Hypertension & Normotension & & Hypertension & Normotension & \\
\hline Pharyngalgia & $16(28.1 \%)$ & $12(20.7 \%)$ & 0.357 & $7(17.1 \%)$ & $6(18.8 \%)$ & 0.853 \\
\hline Myalgia & 13 (22.8\%) & $10(17.2 \%)$ & 0.456 & $8(19.5 \%)$ & $5(15.6 \%)$ & 0.667 \\
\hline $\begin{array}{l}\text { Sputum } \\
\text { production }\end{array}$ & $7(12.3 \%)$ & $4(6.9 \%)$ & & $9(22 \%)$ & $11(34.3 \%)$ & 0.238 \\
\hline Dyspnea & $5(8.8 \%)$ & $3(5.2 \%)$ & & $9(22 \%)$ & $8(25 \%)$ & 0.76 \\
\hline Headache & $8(14 \%)$ & $5(8.6 \%)$ & 0.359 & $4(9.8 \%)$ & $3(9.4 \%)$ & \\
\hline Fear of cold & $4(7 \%)$ & $2(3.4 \%)$ & & $6(14.6 \%)$ & $5(15.6 \%)$ & 0.907 \\
\hline Anorexia & $4((7 \%)$ & $2(3.4 \%)$ & & $4((9.8 \%)$ & $3(9.4 \%)$ & \\
\hline Diarrhea & $5(8.8 \%)$ & $1(1.7 \%)$ & & $3(7.3 \%)$ & $4(12.5 \%)$ & \\
\hline $\begin{array}{l}\text { Chest } \\
\text { tightness }\end{array}$ & $4(7 \%)$ & $4(6.9 \%)$ & & $3(7.3 \%)$ & $4(12.5 \%)$ & \\
\hline Chest pain & $2((3.5 \%)$ & $1(1.7 \%)$ & & $4(9.8 \%)$ & $3(9.4 \%)$ & \\
\hline Retching & $3(5.3 \%)$ & $2(3.4 \%)$ & & $2(4.9 \%)$ & $2(6.3 \%)$ & \\
\hline Palpitation & $4(7 \%)$ & $2(3.4 \%)$ & & $1(2 \%)$ & $1(3.1 \%)$ & \\
\hline Hemoptysis & 0 & 0 & & $2(4.9 \%)$ & $1(3.1 \%)$ & \\
\hline
\end{tabular}

As shown in Table 2, there is no difference in the laboratory data between the mild COVID-19 groups with and without hypertension, but levels of CRP, IL-6, and D-dimer in the severe COVID-19 group with hypertension were significantly higher than in the normotensive severe COVID-19 group $(P<0.05)$. 
Table 2

Comparison of laboratory data between the hypertensive and normotensive groups infected with SARSCoV-2

\begin{tabular}{|c|c|c|c|c|c|c|}
\hline & Hypertension & Normotension & & Hypertension & Normotension & \\
\hline Variable & $\begin{array}{l}\text { Mildly ill } \\
\text { cases }\end{array}$ & $\begin{array}{l}\text { Mildly ill } \\
\text { cases }\end{array}$ & $\begin{array}{l}P \\
\text { value }\end{array}$ & $\begin{array}{l}\text { Severely ill } \\
\text { cases }\end{array}$ & $\begin{array}{l}\text { Severely ill } \\
\text { cases }\end{array}$ & $\begin{array}{l}P \\
\text { value }\end{array}$ \\
\hline $\begin{array}{l}\text { WBC }(\times \\
109 / L)\end{array}$ & $5.59 \pm 2.77$ & $6.27 \pm 2.82$ & 0.383 & $6.31 \pm 2.65$ & $7.29 \pm 2.55$ & 0.451 \\
\hline $\begin{array}{l}\text { LYM (x } \\
109 / L)\end{array}$ & $0.99 \pm 0.54$ & $1.11 \pm 0.44$ & 0.318 & $0.85 \pm 0.31$ & $0.94 \pm 0.38$ & 0.293 \\
\hline CRP (mg/L) & $2.13 \pm 2.19$ & $2.02 \pm 2.85$ & 0.949 & $10.98 \pm 9.01$ & $7.1 \pm 3.51$ & 0.024 \\
\hline $\begin{array}{l}\text { PCT } \\
\text { (ng/mL) }\end{array}$ & $0.22 \pm 0.17$ & $0.26 \pm 0.23$ & 0.179 & $0.42 \pm 0.7$ & $0.36 \pm 0.37$ & 0.784 \\
\hline IL-6 (pg/mL) & $10.67 \pm 5.88$ & $9.2 \pm 5.07$ & 0.254 & $32.16 \pm 15.44$ & $21.2 \pm 16.25$ & 0.007 \\
\hline$D-D(\mu g / L)$ & $3.21 \pm 1.21$ & $2.46 \pm 2.33$ & 0.199 & $6.49 \pm 2.6$ & $4.54 \pm 3.91$ & 0.022 \\
\hline
\end{tabular}

Table 3

Anti-hypertensive drugs used in hypertensive patients with COVID-19

\begin{tabular}{|lllll|}
\hline Drug class & patients $(\mathbf{n}=\mathbf{9 8})$ & Mild cases $(\mathbf{n}=\mathbf{5 7})$ & Severe cases $(\mathbf{n}=\mathbf{4 1})$ & P value \\
\hline CCB & $83(84.7 \%)$ & $49(86 \%)$ & $34(82.9 \%)$ & 0.68 \\
ARB & $25(25.5 \%)$ & $11(19.3 \%)$ & $14(34.1 \%)$ & 0.096 \\
ACEI & $13(13.3 \%)$ & $8(14 \%)$ & $5(12.2 \%)$ & 0.791 \\
\hline -blockers & $12(12.2 \%)$ & $9(15.8 \%)$ & $3(7.3 \%)$ & 0.207 \\
\hline Diuretic & $2(2 \%)$ & 0 & $2(4.9 \%)$ & \\
\hline
\end{tabular}


Table 4

General treatment and outcomes of hypertensive patients infected with COVID-19

\begin{tabular}{|lllll|}
\hline & patients $(\mathbf{n = 9 8 )}$ & Mild cases $(\mathbf{n}=\mathbf{5 7})$ & Severe cases $(\mathbf{n}=\mathbf{4 1})$ & P value \\
\hline Treatment & & & & \\
Oxygen support & $81(82.7 \%)$ & $40(70.2 \%)$ & $41(100 \%)$ & P 0.001 \\
Antiviral therapy & $98(100 \%)$ & $57(100 \%)$ & $41(100 \%)$ & \\
\hline Antibiotic therapy & $85(86.7 \%)$ & $44(77.2 \%)$ & $41(100 \%)$ & 0.001 \\
\hline Glucocorticoid & $31(31.6 \%)$ & $13(22.8 \%)$ & $18(43.9 \%)$ & 0.017 \\
Arbidol & $75(76.5 \%)$ & $45(78.9 \%)$ & $30(73.2 \%)$ & 0.506 \\
\hline Ribavirin & $58(59.2 \%)$ & $30(52.6 \%)$ & $28(68.3 \%)$ & 0.12 \\
\hline Outcome & & & & 0.082 \\
\hline Hospitalization & $35(35.8 \%)$ & $17(29.8 \%)$ & $18(43.9 \%)$ & 0.082 \\
\hline Discharge & $60(61.2 \%)$ & $40(70.2 \%)$ & $20(48.8 \%)$ & \\
\hline Death & $3(3 \%)$ & 0 & $3(7.3 \%)$ & \\
\hline
\end{tabular}

All 188 patients had abnormal chest CT findings during admission. The typical characteristics in the imaging showed solitary or multiple patchy shadows and pulmonary interstitial changes with groundglass opacity and interstitial thickening together with vascular enlargement displaying "slabstone signs." Two patients' chest CT images are shown in Fig. 1; panel A represents the severe group, and panel B represents the mild group. The opaque area of the ground glass is larger and the degree of consolidation is more serious in the severe group.

All of the hypertensive patients received antiviral therapy (98 [100\%]), and most of them received antibiotic therapy (85 [86.7\%]) and corticosteroids (31 [31.6\%]). The majority of patients needed oxygen support (81 [82.7\%]). In the hypertensive group, most patients were given calcium-antagonist (CCB, 83 [84.7\%]) and angiotensin-converting enzyme inhibitors/angiotensin receptor blockers (ACEI/ARBs, 25 $[25.5 \%] / 13$ [13.3\%]) to control blood pressure. There was a significant difference between the severe group and the mild group in the number of patients who received antibiotics and corticosteroids $(p<$ 0.05). There was no significant difference between the severe and mild COVID-19 groups in the number of patients who used antiviral therapy of Arbidol $(p=0.506)$ and ribavirin $(p=0.12)$. At the same time, the two groups (those with severe vs. mild COVID-19) showed no statistically significant differences in the numbers of those on antihypertensive therapy taking ACE I/ARBs, CCB, $\beta$-blockers, and diuretic medicines $(p>0.05)$. As of March 23, 2020, a total of 60 patients $(61.2 \%)$ had been discharged, and 3 patients $(7.3 \%)$ had died.

\section{Discussion}


Hypertension has been widely reported to increase severity and mortality of patients with COVID-19 [10]. Our research found the average age of hypertensive patients was over 60 years old, which was significantly higher than the average age of patients without hypertension. At the same time, we confirmed that the most common symptoms of hypertensive patients infected with COVID-19 were fever, dry cough, and fatigue. In hypertensive patients, low-grade or moderate fever was common and combined with less systemic symptoms. Some studies have found that ACE2 played a negative regulatory role by degrading Ang II into ang (1-7), which had a protective effect on the lung and could prevent or reduce acute lung failure. SARS-CoV infection decreases the expression level of ACE2, so the protective effect of ACE2 is diminished, making patients more prone to acute lung failure [11]. The expression of ACE2 is significantly decreased in patients with hypertension, which might be one of the reasons why these patients had higher risk of developing severe COVID-19. But studies have also confirmed that SARS-CoV-2 enters human cells by binding to the ACE2 receptor. Additionally, studies have shown that some antihypertensive drugs such as ACE I and ARBs may increase the expression level of ACE2 at the cell surface [12]. In theory, the susceptibility of patients with hypertension treated with ACE I or ARBs would therefore increase. But research has shown that the acute lung injury caused by the deletion of ACE2 after SARS-CoV infection can be alleviated by reducing the concentration of angiotensin II [13], so the increased expression of ACE2 caused by treatment with ACE I/ARBs may alleviate the lung injury of SARS-CoV-2 to some extent. In our study, there was no significant difference between the mildly ill and severely ill groups taking ACE I/ARBs, so it can be inferred that the ACE I/ARBs can still be taken by hypertensive patients infected with COVID-19.

There is a certain degree of similarity between SARS-CoV-2 and SARS-CoV. They both cause fever, cough, and fatigue, whereas the upper respiratory symptoms such as pharyngalgia and rhinorrhea were less common [14]. At present, most of the patients with COVID-19 had been proven to have low counts of leukocytes and lymphocytes, especially in severely ill patients [15]. Research has suggested that SARSCoV-2 might act mainly on lymphocytes, especially T lymphocytes, just like SARS-CoV [16]. The virus spreads and infects other cells through the respiratory mucosa, induces cytokine storm in vivo, and produces a series of immune reactions, which lead to changes of peripheral white blood cells and immune cells (such as lymphocytes) [17]. IL-6 is an important lymphokine synthesized by T lymphocytes. It directly mediates the responses of the immune system and plays an important role in viral infection and prognosis [18]. In this study, compared with the mildly ill group, the level of IL-6 in the severely ill group increased significantly, as did the level of D-dimer. This also suggested that severely ill patients might have abnormal coagulation. The activation of the coagulation system might be related to the continuous inflammatory response. This may explain why the level of CRP in response to inflammation was also significantly increased. However, PCT is mainly used to reflect systemic bacterial infection. In viral infection or non-infectious inflammation, the level of PCT does not increase or only increases slightly or moderately, which is consistent with the results of this study [19]. In our research, we also found that in the severely ill group, the levels of CRP, IL-6, and D-dimer in hypertensive patients were significantly higher than those in normotensive patients. Disease severity might be also related to ACE2. Hypertensive patients show decreased ACE2 and inhibited degradation of bradykinin (BK). Increased levels of 
bradykinin and activation of the bradykinin receptor-1 (B1R) by Des-Arg-9-BK can lead to an increase in secretion of pro-inflammatory cytokines associated with endothelial cell inflammation. IL-6 can be significantly increased with Des-Arg-9-BK stimulation, pointing toward a positive feedback loop in which B1R, activated by pro-inflammatory cytokines, can induce and exacerbate endothelial inflammation [20]. At the same time, prolonged hypertension can easily cause target-organ damage such as damage to the heart, brain, and kidneys. Therefore, in the systemic inflammatory response, the compensatory functions of the important organs of the patients with hypertension declines, and they are unable to deal with the inflammatory storm quickly. This is one of the reasons why hypertensive patients with severe COVID-19 are more seriously affected.

Currently, COVID-19 has no particularly effective treatment anywhere in the world. At present, the primary measures to control this disease are early isolation and supportive treatment for affected patients. In this study, all of the hypertensive patients were treated with antiviral drugs with Arbidol and ribavirin. Ribavirin is a guanosine analog with in vitro activity against a large number of highly lethal emerging viruses. Mechanistically, ribavirin inhibits RNA synthesis by viral RdRp and also inhibits mRNA capping [21]. According to the results of virtual screening of FDA-approved drugs against the COVID-19 virus main protease (COVID-Mpro), ribavirin ranked at the second position [22]. Arbidol is a small indole-derivative molecule. Its mechanism involves inhibition of virus-mediated fusion with target membrane and a resulting block of virus entry into target cells $[23,24]$. In some other studies, Arbidol has shown a tendency to improve discharge rates and reduce mortality [25]. In our study, the majority of patients were treated with Arbidol combined with ribavirin and had higher cure rates (61.2\%), so it can be inferred that Arbidol and ribavirin are safe and effective in the early treatment of COVID-19 hypertensive patients. Because of high amounts of cytokines induced by SARS-CoV, MERS-CoV [26, 27], and COVID-19, 18 $(43.9 \%)$ of the severely ill hypertensive patients were treated with glucocorticoids in this study to reduce inflammatory injury in the lungs. However, the evidence from SARS and MERS indicated that the use of glucocorticoids did not improve mortality, but rather delayed viral clearance [28, 29], so use of glucocorticoids is still controversial. Due to the limited sample size of this study, the efficacy and safety of glucocorticoids in hypertensive patients should not be assumed proven.

As the sample sizes of hypertensive and non-hypertensive patients were limited, the statistical analysis results should be interpreted with caution. The $p$ values without statistical significance do not necessarily reflect the exact situation of the whole population. Longer-term observation is required.

\section{Conclusion}

COVID-19 is becoming a global health threat, and there is an increasing risk of overwhelming healthcare infrastructures and jeopardizing patient care even in the most developed countries. Research on hypertensive patients infected with COVID-19 can help better determine prognosis and provide a theoretical basis for individualized treatment. Early diagnosis, timely isolation, and appropriate treatment are the keys to fighting this infection. 


\section{Abbreviations}

COVID-19: coronavirus disease 2019

CRP: C-reactive protein

IL-6: Interleukin-6

ACEI/ARB: angiotensin-converting enzyme inhibitors/angiotensin receptor blockers

ACE2: angiotensin-converting enzyme 2

ARDS: acute respiratory distress syndrome

CCB: calcium-antagonist

SARS-CoV-2: 2019 severe acute respiratory syndrome coronavirus 2

\section{Declarations}

\section{Acknowledgements}

We acknowledge all the health-care workers involved in the diagnosis and treatment of patients in Wuhan. We thank LetPub (www.letpub.com) for its linguistic assistance during the preparation of this manuscript.

\section{Availability of data and materials}

All data that was generated or analyzed during the current study are available from the corresponding author on reasonable request.

\section{Funding}

Our research work is supported by the Joint Medical Research project of Chongqing Science and Technology Bureau \& Chongqing Municipal Health Commission\2019MSXM033『and the Innovative Research Groups project of Chongqing Medical and Pharmaceutical College (YGZ2019402), The Changshou Science and Technology Project (CS2020026), Corona Virus Disease 2019 Prevention and Control Technology Project of Changshou (CS2020XG005).

\section{Authors' contributions}

SW, QZ contributions to conception and design, or acquisition of data, or analysis and interpretation of data, involved in drafting the manuscript; $\mathrm{PW}$ and $\mathrm{H}-\mathrm{HY}$, contributions to conception and design, or acquisition of data, or analysis and interpretation of data; X-QJ, D-YF, PJ, Z-DZ ,T-TL,S-SZ and J-HZ, acquisition of data, or analysis and interpretation of data; Z-BZ, revising it critically for important 
intellectual content; and have given final approval of the version to be published. All authors read and approved the final manuscript.

\section{Ethics approval and consent to participate}

The study has been approved by the ethics committee of Changshou people's Hospital, Chong qing, China.

\section{Consent for publication}

Not applicable.

\section{Competing interests}

The authors declare that they have no competing interests

\section{References}

[1] Huang C, Wang Y, Li X, Ren L, Zhao J, Hu Y, et al. Clinical features of patients. infected with 2019 novel coronavirus in Wuhan, China. Lancet. 395 (2020) 497-506.

[2] Coronavirus Outbreak Available at https://www.worldometers.info/coronavirus/.

Accessed 1 May,2020.

[3] Zaki AM, Van Boheemen S, Bestebroer TM, Osterhaus ADME, Fouchier RAM.Isolation of a novel coronavirus from a man with pneumonia in Saudi Arabia. N Engl J Med. 367(2012) 1814-1820.

[4] Zhu N, Zhang D, Wang W, et al. A novel coronavirus from patients with pneumonia in China, 2019. N Engl J Med. 382 (2020) 727-733.

[5] Wan Y, Shang J, Graham R, Baric RS, Li F. Receptor Recognition by the Novel. Coronavirus from Wuhan: an Analysis Based on Decade-Long Structural Studies of SARS Coronavirus. J Virol 94 (2020).

[6] Li XC, Zhang J, Zhuo JL. The vasoprotective axes of the renin-angiotensin system: Physiological relevance and therapeutic implications in cardiovascular, hypertensive and kidney diseases. Pharmacol Res . 125 (2017) 21-38.

[7] Wang D, Hu B, Hu C, et al. Clinical Characteristics of 138 Hospitalized Patients with 2019 Novel Coronavirus-Infected Pneumonia in Wuhan, China. JAMA - J Am Med Assoc. 323 (2020) 1061-1069.

[8] Lu R, Zhao X, Li J, et al. Genomic characterisation and epidemiology of 2019 novel coronavirus: implications for virus origins and receptor binding. Lancet . 395 (2020) 565-574. 
[9] National health commission of China. Guideline of management of COVID-19

(version3)http://www.nhc.gov.cn/yzygj/s7653p/202001/f492c9153ea9437bb587ce2ffcbee1fa.shtml. Date last updated: January 232020.

[10] Lippi G, Wong J, Henry BM. Hypertension and its severity or mortality in. Coronavirus Disease 2019 (COVID-19): a pooled analysis. Polish Arch Intern Med. 2019 (2020).

[11] Te Riet L, Van Esch JHM, Roks AJM, Van Den Meiracker AH, Danser AHJ. Hypertension: ReninAngiotensin-Aldosterone System Alterations. Circ Res. 116 (2015) 960-975.

[12] Klimas J, Olvedy M, Ochodnicka-Mackovicova K, et al. Perinatally. administered. losartan augments renal ACE2 expression but not cardiac or renal Mas receptor in spontaneously hypertensive rats. J Cell Mol Med. 19 (2015) 1965-1974.

[13] Hamming I, Timens W, Bulthuis MLC, Lely AT, Navis GJ, van Goor H. Tissue distribution of ACE2 protein, the functional receptor for SARS coronavirus. A first step in understanding SARS pathogenesis. $J$ Pathol.203 (2004) 631-637.

[14] Antonio GE, Wong KT, Hui DSC, et al. Imaging of severe acute respiratory syndrome in Hong Kong. Am J Roentgenol .181 (2003) 11-17.

[15] Gao Y, Li T, Han M, et al. Diagnostic utility of clinical laboratory data determinations for patients with the severe COVID-19. J Med Virol. 2020.

[16] Wong CK, Lam CWK, Wu AKL, et al. Plasma inflammatory cytokines and chemokines in severe acute respiratory syndrome. Clin Exp Immunol.136 (2004) 95-103.

[17] Review I. Immune activation and inflammation in HIV-1 infection: 2008: 231-241.

[18] Zhang C, Wu Z, Li JW, Zhao H, Wang GQ. The cytokine release syndrome (CRS) of severe COVID-19 and Interleukin-6 receptor (IL-6R) antagonist Tocilizumab may be the key to reduce the mortality. Int J Antimicrob Agents. 2020.

[19] Mussap M, Degrandi R, Cataldi L, Fanos V, Plebani M. Biochemical markers for the early assessment of neonatal sepsis: the role of procalcitonin. J Chemother . 19 (2007) 35-38.

[20] Mugisho 00, Robilliard LD, Nicholson LFB, Graham ES, O'Carroll SJ. Bradykinin receptor-1 activation induces inflammation and increases the permeability of human brain microvascular endothelial cells. Cell Biol Int. 44 (2020) 343-351.

[21] Totura AL, Bavari S. Broad-spectrum coronavirus antiviral drug discovery. Expert Opin Drug Discov .14 (2019) 397-412. 
[22] Kandeel M, Al-Nazawi M. Virtual screening and repurposing of FDA approved drugs against COVID19 main protease. Life Sci. 251 (2020) 117627.

[23] Blaising J, Polyak SJ, Pecheur El. Arbidol as a broad-spectrum antiviral: an update. Antiviral research. 107(2014) 84-94.

[24] National health commission of China. Guideline of management of COVID-19

(version7)http://www.nhc.gov.cn/yzygj/s7653p/202003/46c9294a7dfe4cef80dc 7f5912eb1989.shtml. Date last updated: March 4 2020. Hui DS. Systemic Corticosteroid Therapy May Delay Viral Clearance in Patients with Middle East Respiratory Syndrome Coronavirus Infection. American journal of respiratory and critical care medicine. 197(2018) 700-701.

[25] Wang Z, Yang B, Li Q, Wen L, Zhang R. Clinical Features of 69 Cases with. Coronavirus Disease 2019 in Wuhan, China. Clin Infect Dis 2020.

[26] Falzarano D, De Wit E, Rasmussen AL, Feldmann F, Okumura A, Scott DP, et al. Treatment with interferon- $a 2 b$ and ribavirin improves outcome in ERS-CoV-infected rhesus macaques. Nature medicine. 19 (2013) 1313-1317.

[27] Faure E, Poissy J, Goffard A, Fournier C, Kipnis E, Titecat M, et al. Distinct immune. response in two MERS-CoV-infected patients: can we go from bench to bedside? PloS one. 9 (2014).

[28] Stockman LJ, Bellamy R, Garner P. SARS: Systematic review of treatment effects. PLoS Med. 3 (2006) 1525-1531.

[29] Hui DS. Systemic corticosteroid therapy may delay viral clearance in patients with middle east respiratory syndrome coronavirus infection. Am J Respir Crit Care Med. 197 (2018) 700-701.

\section{Figures}



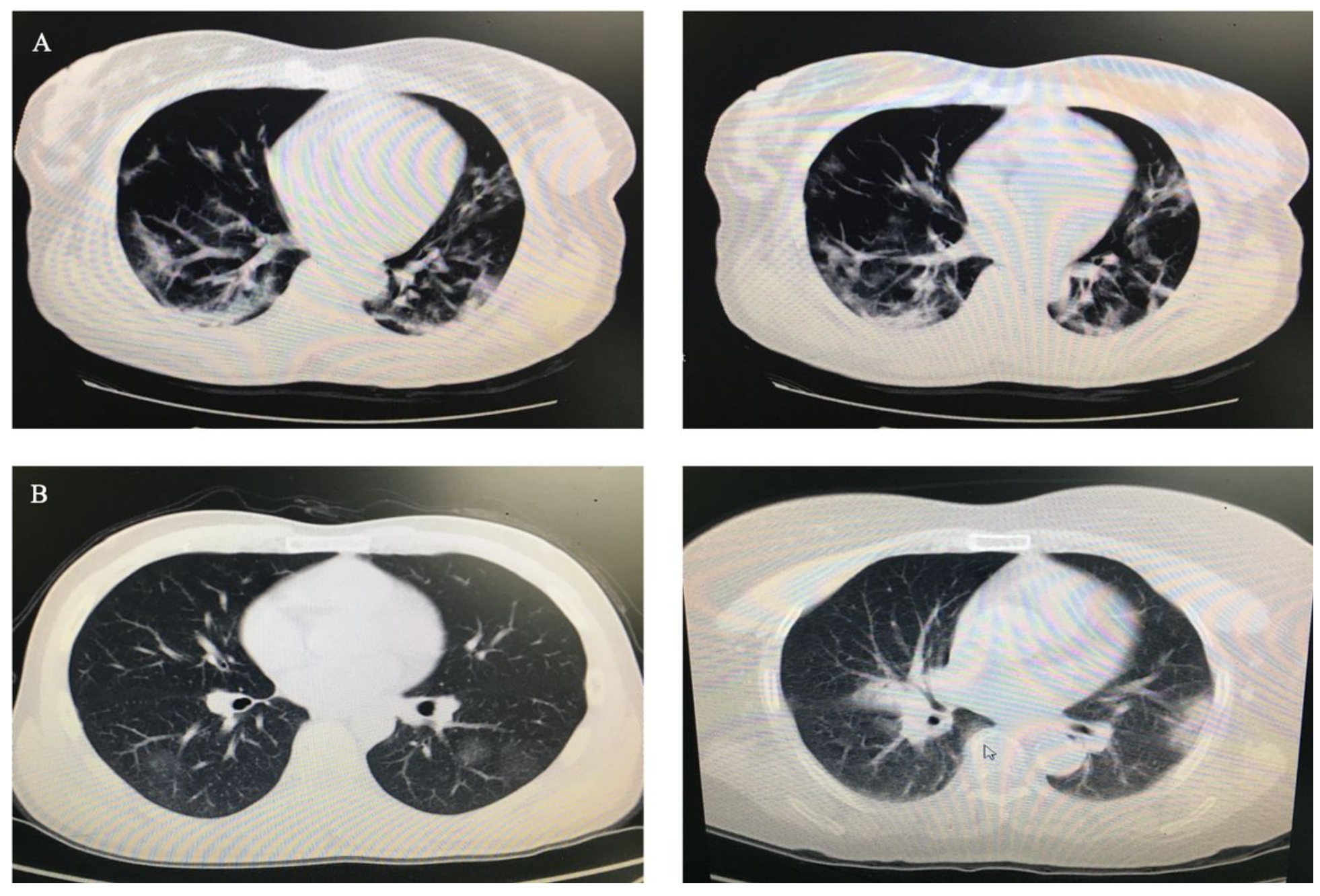

Figure 1

Chest computed X-ray tomography (CT) images of two patients with COVID-19. A. Chest CT images of patients in the severely ill group. B. Chest CT images of patients in the mildly ill group. 